\title{
Service-Learning in Asia
}

Carol Ma Hok Ka, Thera Chiu, and Lim Tai Wei

\section{Service-Learning}

Service-learning (SL) has been recognized as a pedagogy that integrates meaningful community service with academic knowledge and skill development. It is an instructional practice providing a self-reflection platform for different stakeholders to enrich their learning experience, nurture civic responsibility, and strengthen community bonding (Ma, Chan, Mak, Chan, 2018). Globally, higher education institutions (HEI) are integrating SL into their curriculums as significant studies have shown the benefits of this innovative approach to experiential learning (Ma \& Lo, 2016; Kiely, 2005), including enhanced academic learning, communication skills, organizational skills, problem-solving skills, social competence, research skills and civic orientation (Ma \& Chan, 2013; Astin, Vogelgesang, Ikeda, \& Yee, 2000; Vogelgesang \& Astin, 2002 ). It has also generated new knowledge (Hargreaves, 2003), improved leadership skills (Snell, Chan, \& Ma, 2013), and encouraged civic engagement (Steinberg, Hatcher, \& Bringle, 2011).

\section{Service-Learning in Asia}

Although SL is primarily a western learning concept, it is widely used as a pedagogy among education and community sectors in Asia, especially after the academic conference on 'Service-Learning in Asia: Creating networks and curriculum in higher education' held in 2002 at the International Christian University (ICU) in Japan as this became an interconnection with other Asian HEIs (Xing \& Ma, 2010). In 2004, ICU set up the ServiceLearning Asia Network (SLAN) with support from the Japanese Government and the United Board for Christian Higher Education in Asia (Ma, Chan, Chen and Fong, 2018). In 2004, LU received one million dollars (HKD) funding support from Kwan Fong Charitable Organization to start a Service-Learning and Research Scheme (SLRS) and then in 2006, received another ten million dollars (HKD) to set up the first Office of Service-Learning (OSL) in Hong Kong. With the aim of constructing a model for academy-student-community partnership, LU has made an attempt to truly put the inspirational slogan "Serving to Learn and Learning to Serve" into practice. With commitment from a dedicated SL team and support from local and regional partners, LU started taking the lead of SL development in both Hong Kong and Asia. LU even organized the first Asia-Pacific Regional Conference on Service-Learning (APRCSL) in 2007 and served as the secretariat for SLAN after the revitalization.

The biannual APRCSL was established in 2007 as a platform for education institutions and non-profit organization in the Asia-Pacific region to share knowledge and experiences in SL. After a few years of conference, it is also found that Asian countries explore different ways to understand the meanings and the practices of SL. They also realized the unprecedented need 
to modify and adjust to this concept with their own cultures, social and political characteristics.

The themes of the APRCSL are listed below:

- 2007: An Evolving Integration of Theory and Practice

- 2009: Crossing Borders, Making Connections: Service-Learning in Diverse Communities

- 2011: Make a Difference: Impacts of Service-Learning

- 2013: Service-Learning as a Bridge from Local to Global: Connected World, Connected Future

- 2015: Love Journey: Community Engagement through Service-Learning

- 2017: Educating the Heart: Nurturing a Fruitful Life Through Service-Learning

In 2019, the $7^{\text {th }}$ APRCSL hosted by Singapore University of Social Sciences (SUSS) with the support of the Service-Learning Asia Network and different key partners include Lingnan Foundation, SG Cares, Youth Corps Singapore and SkillsFuture SG. The conference theme was 'Service-Learning: A Lifelong Journey of Social Responsibility'. As the organizer and the secretariat of the SLAN, SUSS noticed increasing societal and environmental challenges, the need to influence and empower Asian youths to actively develop and act on their sense of social responsibility is ever pressing. In both academic and co-curricular applications, SL could play a critical role in HEIs in educating and engaging our youths to develop the knowledge and skills (Head), attitudes and dispositions (Heart) to make life choices that are socially responsible (Habit), in their journey of growth to become leaders in society. Since the whole region is facing similar social problems like poverty gap, ageing population, global warming, energy shortage and food crisis, environmental issue. SL provides a very good platform for students to take action beyond the campus environment, visualize the world as their home and become social leaders to spread love, care and act for the good of people in need.

\section{Articles in this Issue}

$\mathrm{Lu}$, Chen and Yang took a group of Macau students out of their comfort zone and went to the mountain area of China to experience the life of ethnic minority children through a SL teaching project. The authors have shown the real life experiences to the students, thus, the students had more understanding of poverty issues and education opportunities in China's rural areas. Through the SL project, students also developed their teamwork spirits, leadership and service skills. And the most important is they have commitment to continue to serve because they understand SL must be a mutual process. The SL experience not only empowered the students, but also let them understand how a living-learning community can be created to educate people holistically. 
Living-learning community can happen anytime if we show respect to each other, for example, intergenerational learning. In view of the ageing population, especially, the increasing longevity and persisting low fertility have given rise to the whole ageing population in the world, there is a demand to promote more intergenerational harmony. Au Yeung, Lam and Fong shared how they have created a learning platform for young-old work together in a Science course. The authors tried to explore how elderly individuals participating in a SL project facilitates open communication and reciprocal learning between age groups, and promotes intergenerational harmony. The young old partnership in the SL project has not only enhanced the trust and communication, but also help to promote a sustainable society. Their findings echoed to what Chan et al (2013)'s research result that 'Through learning, investigating, communicating and solving problems together, students and elders cooperate and complete the learning journey hand in hand." It is a positive experience while young-old work together.

However, not every SL project can run it smoothly. There are still substantial challenges (e.g. recognition of faculty and students' involvement in SL; sustainability issues, ethical conduct of SL, etc. have not been sought for approval/cooperation with school authorities) to conduct $\mathrm{SL}$ in the region. Uy's article is an example to talk about the enablers and barriers in implementing SL in the context of a premier private Catholic Philippine allied health profession education institution. She also highlighted the multi-dimensional perspectives from the academic community of faculty members, students and the partner communities regarding many key concepts which may affect the SL implementation. While the benefits of SL are clear to the academic landscape, it was apparently not adequate to drive its successful implementation to attain its graduate outcomes as well as the resultant disability-related health outcomes for the communities we serve. The results of her study can inform development of continuing education, training and support for considering SL as its signature pedagogy in the allied health profession. She re-emphasized that SL can potentially support allied health profession curriculum for its emerging professional identity and role in enhancing disability-related health outcomes.

Other than integrate SL into your curriculum, you can also use SL as a way of conducting a community engaged research. Loan and Hsu tried to explore how civic media practice facilitating the democratic process in environmental protection in Taiwan through community engaged research. The authors conducted in-depth interviews and analyzed the posts on Facebook group, LINE messages, and websites of two ongoing projects regarding the impact of civic media practice on the democratic process. They also analyzed how social networking sites or applications function in four activities of the democratic process through network building, discussion forums, distributed ownership and persistent input. These activities definitely help organizations overcome distrust of institutions and enhance civic media's ability to foster connections and create more usable interfaces between communities and institutions. Nevertheless, creating a good space for discussion where people can voice their concerns is necessary, however, how to create a transparent, open and fair space between the participants and the administers are always a question? So, research may help to suggest what 
would be the best to provide a safe environment to express views and concerns. And it may also mitigate the harm to democratic processes as well.

\section{Conclusion}

Though SL has been spreading in the region, there are not enough discussions on how can SL enhance teaching and learning to serve the needy in the society. The articles in this issue are some examples in the region, other challenges and opportunities should be shared in order to create the best practices for the region. In 2017, a presidential meeting of SLAN was held to discuss the development and best practices of SL in the region. It was confirmed that Silliman University in Philippines and Dongseo University in Korea will host the next regional conferences in 2021 and 2023 respectively. Looking ahead, it is important to develop more joint partnerships and platforms to highlight the importance of SL as it will definitely be one of the means to address disruptions in the contemporary world and complex social issues. As you read this issue, we hope that you can consider the following questions: What are the needs in the region? Ageing issues? Environmental issues? Democracy? Children education or other else? What make SL work? How can we support SL movement? And what and how the HEIs recognize faculty members and students to embrace SL? Hopefully, with your reflection, we can get more insights from you in the next regional conference in 2021 in Philippines. 


\section{References}

Astin, A., Vogelgesang, L., Ikeda, E., \& Yee, J. (2000). How service-learning affects students. Los Angeles, CA: Higher Education Research Institute, UCLA.

Hargreaves, A. (2003). Teaching in the knowledge society: Education in the age of insecurity. New York, NY: Teachers College Press.

Kiely, R. (2005). A transformative learning model for Service-Learning: A longitudinal case study.Michigan Journal of Community Service-Learning, 12(1), 5-22.

Ma, C. H. K. (2018). Service-Learning development in Higher Education in Hong Kong. In Hong Kong in 2017: Two Decades of Post-1997 Hong Kong Developments (pp. 43-61). Singapore and New Jersey: WSPC.

Ma, C. H. K., Chan, A. C. M., Liu A. C., \& Mak F. M. F. (2018). Service-Learning as a New Paradigm in the Higher Education of China. East Lansing, MI: The Michigan States University Press

Ma, C. H. K., \& Lo, D. Y. L. (2016). Service-Learning as an Independent Course: Merits, Challenges, and Ways Forward. International Journal of Research on Service-Learning and Community Engagement, 4(1), 39-52.

Meijs, L. C. P. M., Maas, S., \& Aramuruzabala, P. (2019) Institutionalisation of service learning in European higher education. In. Embedding service learning in European Higher Education: Developing a culture of civic engagement (pp. 212-229). London: Routledge. doi: 10.4324/9781315109053-14.

Steinberg, K. S., Hatcher, J. A., \& Bringle, R. G. (2011). Civic-Minded Graduate: A north Star. Michigan journal of Community Service-Learning, 18(1), 19-33.

Snell, R. S., Chan, Y. L., \& Ma, H. K. C. (2013, June). Learning service leadership through service-learning: Anxieties, opportunities and insights: Paper presented at 4th Asia-Pacific Regional Conference on Service-Learning: Service-Learning as a Bridge from Local to Global: Connected world, Connected future, Hong Kong and Guangzhou, China.

Shek, T. L. D., \& Hollister, M. R. (2017). University Social Responsibility and Quality of Life. A Global Survey of Concepts and Experiences. Singapore: Springer Nature.

Stanton, T., Giles, D., \& Cruz, N. I. (1999). Service-Learning: A Movement's Pioneers Reflect on Its Origins, Practice, and Future. San Francisco, CA: Jossey-Bass Publishers.

Vogelgesang, L. J., \& Astin, A. W. (2000). Comparing the effects of community service and service-learning. Michigan Journal of Community Service Learning, 7, 25-34. 
Xing, J., \& Ma, H. K. C. (2010). Service-Learning in Asia: Curricular Models and Practices. Hong Kong: Hong Kong University Press. 


\section{Author Information}

Carol Ma Hok Ka

Head, Master \& PhD of Gerontology Programme

Senior Fellow, Office of Service-Learning and Community Engagement

Centre for Experiential Learning

S R Nathan School of Human Development

Singapore University of Social Sciences

463 Clementi Road

Singapore 599494

carolmahk@suss.edu.sg

Thera Chiu

Associate Professor

Center for General Education

Taipei Medical University

250 Wuxing St.

Taipei 11031, TW

thera@tmu.edu.tw

Lim Tai Wei

Associate Professor

Centre for University Core

Singapore University of Social Sciences

463 Clementi Road

Singapore 599494

limtaiwei2009@gmail.com 